\title{
Study on the Development and Spread of New Media Art under the Background of Big Data
}

\author{
Yan Hou \\ Qilu Normal University, Jinan, Shandong, 250014, China. \\ 122365871@qq.com
}

\begin{abstract}
Although studies on new media have become a hot topic in academia, most of them are very superficial. As a research direction of communication science, new media researchers should also work hard to find and verify the knowledge about the social phenomenon of information dissemination that is not yet understood by human beings. Fundamental changes have taken place in media communication in the era of Big Data; especially the application of new media has greatly promoted the resource acquisition and information mining of Big Data. Starting from the definition of new media, this paper attempts to explain the development of new media and the main spreading forms of new media and discusses the risks of the spread of new media under the background of Big Data.
\end{abstract}

Keywords: Big Data; New Media; Spread; Risk.

\section{Introduction}

In 1980, Alvin Toffler, a famous scholar, formally proposed the concept of "Big Data" in his book The Third Wave. Until 2009, Big Data became more and more popular with the development of network technology and was widely recognized by people around the world [1]. In September 2015, the State Council issued The Program of Action to Promote the Development of Big Data, which made clear that it would promote the development and application of Big Data in our country and speed up the construction of a powerful data power. With the advent of the era of Big Data, communication industry is the first to bear the brunt. In the past, news communication is based on relatively deep and less data resources, and there was a relatively fixed pattern for the spread speed and interpretation of information. However, under the background of Big Data, the rapid development of new media and the acceleration of globalization require that our new media art industry should take full consideration of the market mechanism, start from the actual situation of the slow development of the new media art industry in China, standardize the market and industrial chain, and train their own innovative talents to effectively promote a continuous, rapid and coordinated development of the new media industry. Therefore, this paper makes an in-depth study on the subject of new media art development and communication and discusses the risks of the spread of new media under the background of Big Data.

\section{Definition of New Media Art}

The new media art under the background of Big Data has a very wide range. It is difficult to describe it with accurate words. It mainly refers to the virtual art images and multimedia products and behaviors created by new technology. The new media art is a very new art form. Under the background of Big Data, this new media art becomes very dependent on technology, but its high interaction determines that it can connect the audience and the work in a variety of artistic forms [2]. Compared with traditional art forms, it has incomparable advantages. The life of the new media art lies in its interactivity. The lack of interactive works of art cannot be regarded as a successful new media art. 


\section{Spreading Forms of New Media Art}

\subsection{Digital Art}

The official definition of digital art refers to arts based on digital technology, which uses optical and electronic media as the basic language. Digital art can create a series of digital artistic works, so it is also an integral part of contemporary art [3]. Through the new media art, artists can express their own art theory externally. Most of their works are the products of the combination of spirit and material, which are reflected in image works, digital works and multimedia devices. Under the background of Big Data, digital art emphasizes the interaction between the works and the audience, and the most rapid development of digital art is a very interactive animation art.

\subsection{Network Art}

The development of network art is inseparable from the rapid development of Internet in recent years. There are various forms of network art. Our most common online games, electronic advertisements and web pages belong to the category of network art. In the past, the web page design of the Internet was mostly static, which paid attention to the tidiness of the web interface and the integrity of information. In order to pursue higher visual effects and enhance the effect of information dissemination, the current webpage design is almost all done by dynamic web page effect.

\subsection{Image Art}

The popularity of DV brings people a new way to disseminate information. People can take their own video and upload them to the network, and the general public can download these videos through the network. Of course, these videos can also be transmitted by television, and the most traditional way of information dissemination is interpersonal communication, spreading face-to-face. It is worth mentioning that the development of art exhibition also provides a good way to display works for electronic image art works.

\subsection{Mobile Media Art}

The mobile media art, which may sound strange to us, is very common in our life, as large as the LED ads on the streets and buildings, and as small as the mobile TV that can be seen everywhere on the vehicle. Of course, it also includes our commonly used advertising games on mobile phones and tablets. In the context of mobile media, the art is mostly spread through apps that people download from the app store to get information about music, news, entertainment, finance, and so on. Of course, we also have the most commonly used QQ, WeChat, micro-blog and so on. It is also a new way of making friends under the background of Big Data.

\section{Spreading Paradigm of the New Media Under the Background of Big Data}

Kuhn, a famous Western philosopher of science, introduced the concept of "paradigm" creatively in The Structure of Scientific Revolution, which refers to the choice, organization and display of experience and information. Spreading involves some kind of media or some form of technology, and messages usually are spread in some form, that is, paradigm. In short, the spreading paradigm is the way in which communication can be constructed. In the era of Big Data, new media also presents different paradigms from traditional media.

\subsection{From the Public Communication Based on the Mobile Internet to The Interpersonal Network Communication under the Social Media}

In the era of Big Data, the pattern of Internet has entered a new stage of superposition and fusion of broadband network, mobile communication network, Internet of things, cloud computing, big data and so on. The social communication based on mobile Internet has become one of the most important development trends of public relations and communication environment. 
With the advent of the Big Data era, the form of Internet has gradually shifted to social media. This is the most critical change in the Internet brought by big data technology. The main body of social media has become a network user, no longer a website's media or an operator. Forums, games, instant messaging, blogs, video sharing and even e-commerce based on technology such as RSS, SNS and micro-blog are social media applications. This portal cannot only carry out two-way information exchange between individuals and the outside world, but also provide a platform for building social relations, or a place for Internet life and work. Individuals become the "center" of information dissemination, representing the era of new media, and the mass communication mode with the center of discourse based on portal websites will gradually decline. Different from the point to face mode of mass communication, the dissemination of information in social media will be more based on the personal social network. The interpersonal network has become the "infrastructure" of mass communication.

\subsection{From the Single Media Attached to Commercial Operation to The Whole Media Industry Chain Supported by Science and Technology}

In the traditional media era, most of the media are independent. Their survival depends on advertising management and the market competition with the homogeneous media, which has the characteristics of insufficient innovation and simple profit mode. The arrival of the Big Data era challenges the capacity of the new media to organize and operate. The operation of the new media depends on the analysis and management of key data in the media competition environment, so as to make the best decision. The key is to integrate the traditional business data and new data, and make a comprehensive analysis on customers, which can further improve user experience and sales performance. Therefore, under the background of the Big Data, the new media needs to establish a complete industrial chain, to carry on the differential and diversified small mass production of the communication content, even to meet the customization needs of the individual users. The new media terminals, such as mobile phones, have laid a solid foundation for the construction of the industrial chain of new media communication technology, and the total amount of the new media market is growing rapidly. In the good environment of the great development of national cultural industry, the new media has become an irreversible trend by establishing a mass information base to form a cooperative and win-win business mode.

\subsection{From Unidirectional Communication between Media and Audiences to Two-Way Interactive Communication: Social Media Opens the Era of "User Centered"}

The biggest change of social media for news production and consumption is the centralization of individual users. The rising power of citizen journalism will lead to qualitative changes in the mode of production of the media industry in the future. It is mainly reflected in the following aspects: firstly, the complete news reports or comments on the blog and micro-blog platform with certain news quality are accepted by the professional media, and the value orientation of the professional media reporting activities is influenced. Secondly, the news clues that netizens inadvertently provide on their personal gateways help the media determine the subject and initiate reporting. Thirdly, netizens participate in online surveys though personal portals, providing public opinion materials and tendencies for news reports. Finally, according to their personal preferences, netizens forwarded the news that they are interested in through forums, blogs, and WeChat, which helped the news spread, and the related comments also realized the appreciation and promotion of the news.

\section{The Risks of the Spread of New Media under the Background of Big Data}

\subsection{Digitalization, Dependence and Fragmentation Caused by Nonlinearity}

The biggest difference between new media and traditional media lies in the full digitalization of information dissemination, and information recipients can freely choose information on any section. Mobile phones, tablet computers and other portable mobile terminals make the time and space become fragmented, and people's use of fragmented time become the norm in information 
consumption. At the same time, although nonlinearity provides a more convenient way to intercept information, it may also lead to fragmentation of information reading and thinking. It is difficult for people to understand and accept longer articles or information that require strict logical thinking.

As mentioned above, the new media has opened up the "user centered" communication pattern, but most of the information from individual users is fragmented. Such big data need long time accumulation, collection and maintenance in order to have the value of mining, which can more truly reflect the users' social attributes, behavior rules, interactive features, and further analyze and explore effective media contents and advertising marketing communication. In the future, big data technology needs to work hard to solve this problem.

\subsection{The Distortion of Communication Information Caused by Interactivity}

In the Big Data environment, the new media communication has shown an obvious "ripple effect", and a piece of simple information can quickly cause explosive effect on the network. From the perspective of user experience, it is precisely the interaction between the sender and receiver of information that is the most attractive feature of new media. These live broadcasts from the public perspective, spread through social media, their influence will be geometrically increased. At the same time, all kinds of rumors and false information are also increasing, which have caused the risks of new media communication. Micro-blog and other personal portals have become the center of the news communication, and the dissemination of the agenda setting has changed greatly, which is followed by the weakening of the authority of the news and even circulate erroneous reports, which has caused the bad influence of public opinions. Therefore, the new media should not only use big data technology to expand the impact of its own communication, but also establish an early warning mechanism and system for emergency public news events. It can effectively control the possible negative effects of the new media communication and solve the crisis through technical means.

\subsection{Disclosure of Personal Privacy Information Caused by Data Platform}

In recent years, social networks, as the representative of the new media, have gradually become integrated social platforms and media platforms. The emergence of social networks makes private living space and network public space overlap. In the Big Data environment, the new media give full paly to technical means to fully understand the users' behaviors and preferences through the depth analysis of the user data, thus making the targeted news production an inevitable trend. In this process, it is easy to personal information and even the business confidential of enterprise users. Privacy issues are mainly reflected in the continuous upgrading and development of new media with high participation such as search engines and social platforms. Therefore, the privacy issues brought about by Big Data must be given full attention.

\section{Conclusion}

New media is an interactive digital composite media based on digital technology and network technology. In the era of Big Data, the data will become the "rich mine" and the core resource of the media, and the new media also presents a communication paradigm different from the traditional media, but there are also risks that cannot be ignored. The development of new media in the era of Big Data is faced with both technical problems and strategic reconfiguration, which will have a profound impact on the future media ecology and development pattern.

\section{References}

[1]. Babbie, E. R., the Practice of Social Research (11th Ed.), Belmont, CA, Thomson Wadsworth, 2007.

[2]. McGuire, W. J., Creative Hypotheses Generating in Psychology: Some Useful Heuristics, Annual Review of Psychology, 1997, No.48, pp.1-30. 
[3]. Tong Bing, News Communication under the Background of New Media, Journalists, 2012(10).

[4]. Chen Changfeng, Liu Shao Hua, How to Do News in the Era of Big Data? News and Writing, 2013(1).

[5]. Ding Ming, Study on the Innovation Mode of New Media Art Industry under the Background of Big Data, Radio and TV Journal, 2015 (12):158. 